\title{
Breakfast and Other Meal Consumption in Adolescents from Southern Poland
}

\author{
Agnieszka Ostachowska-Gasior ${ }^{1, *}$, Monika Piwowar ${ }^{2}$, Jacek Kwiatkowski ${ }^{1}$, Janusz Kasperczyk ${ }^{3}$ \\ and Agata Skop-Lewandowska ${ }^{1}$ \\ 1 Department of Hygiene and Dietetics, Medical College, Jagiellonian University, 7 Kopernika St., \\ Krakow 31-034, Poland; jackwi@poczta.onet.pl (J.K.); agata.skop-lewandowska@uj.edu.pl (A.S.-L.) \\ 2 Department of Bioinformatics and Telemedicine, Medical College, Jagiellonian University, 16 Lazarza St., \\ Krakow 31-034, Poland; mpiwowar@cm-uj.krakow.pl \\ 3 School of Medicine with the Division of Dentistry in Zabrze, Medical University of Silesia, 19 Jordana St., \\ Zabrze 41-808, Poland; jkas@mp.pl \\ * Correspondence: agnieszka.ostachowska-gasior@uj.edu.pl; Tel.: +48-12-422-3720
}

Academic Editor: María M. Morales Suárez-Varela

Received: 15 January 2016; Accepted: 28 March 2016; Published: 28 April 2016

\begin{abstract}
The aim of the study was to evaluate the frequency of breakfast and other meal consumption by adolescents and to assess the relationship between the first and the last meal consumption and sex, body mass index (BMI), and middle school and high school students' education level. The study was conducted in 2013-2014 among 3009 students (1658 girls and 1351 boys) from middle s and high schools in Krakow and Silesia (Poland). The data was obtained from questionnaires that were analyzed with a logistic regression model for measurable and dichotomous variables. Breakfast consumers were seen to eat other meals (second breakfast, lunch, dessert, supper) significantly more often than breakfast skippers. The main meal consumption habits depend on sex and change as adolescents age. Being a girl and a high school student predisposed participants to skip breakfast and supper more often. The BMI of breakfast consumers does not differ significantly from the BMI of breakfast skippers, so BMI might thus not be a sufficient marker of breakfast consumption regularity and dietary habits in an adolescent group. The importance of regularly eaten meals, especially breakfast, together with adequate daily dietary energy intake are beneficial for physical and psychological development and cannot be overestimated in nutritional education and it is necessary to promote healthy eating behavior for well-being in later adult life.
\end{abstract}

Keywords: adolescents; eating behavior; breakfast skipping; meal consumption habits

\section{Introduction}

Adolescence is a particularly unique period of life because it is a time of intense physical, psychosocial and cognitive development. The peak of growth is generally between 11 and 15 years for girls and 13 and 16 years for boys. During this period adolescents gain up to $50 \%$ of their adult weight, more than $20 \%$ of their adult height, and $50 \%$ of their adult skeletal mass [1]. Therefore, a balanced diet and eating meals regularly are both extremely important elements during this period of life [2,3]. Adolescence is also a time of greater autonomy, changing lifestyle and dietary habits. Those changes affect both nutrient needs and intake [4,5]. Some dietary patterns appear to be quite common among adolescents: frequent snacking (usually energy-dense foods); habitual meal skipping (particularly breakfast); late night dinner eating or irregular meal consumption; wide consumption of fast and highly processed foods and unconventional dietary practices [6,7]. Regardless of family income, adolescents of both sexes are at the risk of both dietary excesses (total fat, saturated fatty acids, cholesterol, sodium, table sugar) and deficiencies (fruit, vegetables, iron and calcium-rich foods) [8,9]. In Poland 
the majority of rural schoolchildren and adolescents aged 9-13 have poor dietary habits, including breakfast skipping, high consumption of sweets, and low consumption of fruit and vegetables $[10,11]$. There is a strong positive association between irregular breakfast eating and the risk of excess weight gain as the first step to obesity and metabolic disorders, diabetes, cardiovascular diseases [12-18]. In this aspect, the maintenance of balance between energy intake/output and adequate food daily intake is significant and breakfast has been considered to be an important factor for energy intake regulation [19]. Reduced breakfast energy intake is associated with higher total daily energy intake and when breakfast is skipped it can be difficult to compensate later during the day [20]. Studies have shown that breakfast is an important source of energy and nutrients after an overnight fast and can be helpful in achieving better concentration and better performance at school [21,22]. All environmental determinants which significantly lower their risk of excess weight gain are considered to be helpful for adolescent psychical and physical development [14,23,24]. Family and school play a significant role. It is confirmed that regular family meals positively impact the adolescent diet quality. Regular family meals during the transition from middle school to high school are associated with greater frequency of consuming breakfast and dinner meals and increased intakes of vegetables, dietary fiber, and several key nutrients, including calcium, magnesium, potassium, iron, and zinc [25]. School is the next place that influences the adolescent lifestyle, nutritional habits and meal patterns. School nutrition programs were launched in order to improve quality of school meals and to educate students about the impact of food on their health [26-28].

The main purpose of the study presented here was to evaluate the frequency of regular consumption of meals (breakfast, second breakfast, lunch, dessert and supper) by adolescents attending middle schools and high schools in Poland. A secondary purpose has been to evaluate the relationship between the first and the last meal (breakfast and supper) consumption and sex, BMI and level of education.

\section{Materials and Methods}

\subsection{Survey Design and Sample}

The examination included 3009 students from two university towns in Southern Poland: Krakow and Zabrze Silesia. The group comprised 1658 girls and 1351 boys aged 13-17 (mean age $15.95 \pm 1.58$ ) and with BMI $20.9 \pm 3.2 \mathrm{~kg} / \mathrm{m}^{2}$. A survey was carried out between September 2013 and June 2014 (Table 1) using an anonymous standardized self-completed questionnaire concerning dietary habits. All students were explained the purpose of the survey and the privacy protection policy of personal and enrollment data were ensured. All subjects gave their informed consent for inclusion before they participated in the study, which was conducted in accordance with the Declaration of Helsinki, and The Committee for Human Research of Jagiellonian University, Medical College in Krakow approved the protocol. In accordance with Polish legal regulations this kind of study is not considered a medical experiment and Ethical Committee agreement was not obligatory for medical doctors and dentists ("Dziennik Ustaw" 2011 with modifications; No. 277, line 1634). Participants completed the questionnaire in the classroom, and were provided with a verbal description of the study, and given the chance to ask questions prior to participation. The definition of each meal together with the indication of time during a day when it is usually consumed was presented in the questionnaire. The main meals (breakfast, lunch, supper) were defined as meals being the source of protein, fats, carbohydrates. Breakfast (more than a glass of milk or juice), as a meal that is eaten within one hour after getting up. Second breakfast, as a small meal before midday. Lunch, in Poland, defined as a hot dish consumed between 1 p.m. and 5 p.m. Dessert as a sweet meal or a fruit and supper as an evening meal providing about $20 \%$ of daily energy intake. Participants answered questions about the quantity of meals they usually consume. They were also asked to describe the composition of each meal, but the information about the serving size was not obligatory. Adolescents who did not consume breakfast at all or less than three times a week were categorized as breakfast skippers, and 
the rest of participants were classified as breakfast consumers. The same rules of qualification have been taken into consideration during the estimation of other meals consumption. Height and weight measurements have been taken by trained research staff using standardized protocols. Participants had an empty bladder, did not eat or drink anything three hours before measurements, and were asked to remove shoes and heavy garments before the measurement. Body weight has been measured to the nearest 0.1 kilogram using a digital scale (Model 882; Seca Corporation, Hamburg, Germany). Body height has been measured to the nearest 0.1 centimeter using a free-standing portable stadiometer (Model 214; Seca Corporation). From body weight and body height Body Mass Index (BMI) was calculated using a standard formula: weight $(\mathrm{kg}) /$ height $(\mathrm{m})^{2}$. Acquired data was compared against the baseline values for a population of Polish adolescents [29]. Percentiles specific to age and sex classify children as underweight ( $<5$ th percentile), healthy weight (5th-85th percentile), overweight (85th to $<95$ th) and obesity ( $\geqslant 95$ th percentile). Examined adolescents with BMI $<5$ th percentile and $\geqslant 85$ th percentile were classified as out of the norm.

Table 1. Age and anthropometric data for adolescents enrolled in the study $(n=3009)$.

\begin{tabular}{|c|c|c|c|c|c|c|c|}
\hline \multirow{3}{*}{\multicolumn{2}{|c|}{ Kind of School }} & \multicolumn{4}{|c|}{ Sex } & \multirow{3}{*}{$\Sigma$} & \multirow{3}{*}{$\begin{array}{l}\text { Measurable Variable } \\
\quad(\text { mean } \pm \text { SD) }\end{array}$} \\
\hline & & \multicolumn{2}{|r|}{ Female } & \multicolumn{2}{|r|}{ Male } & & \\
\hline & & $n$ & $\begin{array}{l}\text { Measurable Variable } \\
\quad(\text { mean } \pm \text { SD) }\end{array}$ & $n$ & $\begin{array}{l}\text { Measurable Variable } \\
\quad(\text { mean } \pm \text { SD) }\end{array}$ & & \\
\hline \multirow{8}{*}{ School } & \multirow{4}{*}{$\begin{array}{l}\text { High } \\
\text { school }\end{array}$} & \multirow{4}{*}{1160} & Weight: $57.1 \pm 8.1(\mathrm{~kg})$ & \multirow{4}{*}{1004} & Weight: $71.4 \pm 12.1(\mathrm{~kg})$ & \multirow{4}{*}{2164} & \multirow{9}{*}{$\begin{array}{l}\text { Weight: } 60.8 \pm 12.7(\mathrm{~kg}) \\
\text { Height: } 169.9 \pm 9.5(\mathrm{~cm}) \\
\text { BMI: } 20.9 \pm 3.2\left(\mathrm{~kg} / \mathrm{m}^{2}\right) \\
\text { Age: } 16.8 \pm 0.80 \text { (years) }\end{array}$} \\
\hline & & & Height: $166.5 \pm 6.0(\mathrm{~cm})$ & & Height: $179.1 \pm 6.8(\mathrm{~cm})$ & & \\
\hline & & & BMI: $20.6 \pm 2.7\left(\mathrm{~kg} / \mathrm{m}^{2}\right)$ & & BMI: $22.2 \pm 3.3\left(\mathrm{~kg} / \mathrm{m}^{2}\right)$ & & \\
\hline & & & Age: $16.8 \pm 0.8$ (years) & & Age: $16.8 \pm 0.80$ (years) & & \\
\hline & \multirow{4}{*}{$\begin{array}{l}\text { Middle } \\
\text { school }\end{array}$} & \multirow{4}{*}{498} & Weight: $50.9 \pm 8.4(\mathrm{~kg})$ & \multirow{4}{*}{347} & Weight: $56.6 \pm 12.0(\mathrm{~kg})$ & \multirow{4}{*}{845} & \\
\hline & & & Height: $161 \pm 7.0(\mathrm{~cm})$ & & Height: $166.5 \pm 7.9(\mathrm{~cm})$ & & \\
\hline & & & BMI: $19.3 \pm 2.6\left(\mathrm{~kg} / \mathrm{m}^{2}\right)$ & & BMI: $20.3 \pm 3.5\left(\mathrm{~kg} / \mathrm{m}^{2}\right)$ & & \\
\hline & & & Age: $13.8 \pm 1.0$ (years) & & Age: $13.9 \pm 1.0$ (years) & & \\
\hline \multicolumn{2}{|c|}{$\sum \mathrm{n}$} & 1658 & - & 1351 & - & 3009 & \\
\hline
\end{tabular}

\subsection{Statistical Analysis}

Differences between categorical variables have been tested by chi-square test (Table 2). Two models of multiple logistic regression analysis have been calculated:

\subsubsection{Model 1}

Dependent variable: breakfast consumption.

Independent variables: sex, BMI and age range (expressed as level of education), second breakfast, lunch, dessert and supper consumption.

\subsubsection{Model 2}

Dependent variable: supper consumption.

Independent variables: sex, BMI and age range (expressed as level of education), breakfast, second breakfast, lunch, dessert consumption.

Crude odds ratios (OR) have been calculated to evaluate the risk of independent variables and associated $95 \%$ confidence intervals. Multivariate logistic regression models have been used to adjust for the possible confounding influences among the independent variables on the dependent in model. Variables with significant independent predictive values $(p<0.05)$ were identified. A probability $(p)$ value of $<0.05$ was regarded as statistically significant, $p$-value $>0.05$ has been assigned as not significant (NS). Statistical analysis has been performed with $\mathrm{R}$ software-2.15.3 version [R Core 
Team (2015), R: A language and environment for statistical computing. R Foundation for Statistical Computing, Vienna, Austria. URL https:/ /www.R-project.org/], GLM procedure.

\section{Results}

The descriptive characteristics of the participants are presented in Table 1.

\subsection{BMI of Participants}

The range of BMI in the examined adolescents is presented in Table 2. BMI out of the norm was observed for $18.7 \%$ of all examined students and $70.1 \%$ of them were overweight. Overweight was more often seen among boys. Both underweight and overweight adolescents were more often seen in the older age group (high schools students).

Table 2. BMI range in examined adolescents from middle and high schools.

\begin{tabular}{ccccc}
\hline \multicolumn{2}{c}{ Adolescents } & \multicolumn{3}{c}{ BMI } \\
\hline \multicolumn{2}{c}{ Sex and Level of Education } & Underweight $\boldsymbol{n}$ & Normal $\boldsymbol{n}$ & Overweight $\boldsymbol{n}$ \\
\hline \multirow{2}{*}{ Female } & Middle school & 11 & 458 & 29 \\
\cline { 2 - 5 } & High school & 83 & 924 & 153 \\
\hline \multirow{2}{*}{ Male } & Middle school & 7 & 287 & 53 \\
\cline { 2 - 5 } & High school & 14 & 778 & 212 \\
\hline \multirow{2}{*}{ All Examined $\boldsymbol{\Sigma} \mathbf{n}(\boldsymbol{\%})$} & $\mathbf{1 1 5} \mathbf{( 3 . 8 \% )}$ & $\mathbf{2 4 4 7} \mathbf{( 8 1 . 3 \% )}$ & $\mathbf{4 4 7}(\mathbf{1 4 . 9 \% )})$ \\
\hline \multicolumn{2}{c}{ All examined female $\Sigma \mathrm{n}$} & 94 & 1382 & 182 \\
\hline \multicolumn{2}{c}{ All examined male $\Sigma \mathrm{n}$} & 21 & 1065 & 265 \\
\hline
\end{tabular}

Underweight-BMI $<$ 5th percentile; Normal-BMI 5th-85th percentile; Overweight-BMI $\geqslant 85$ th percentile.

\subsection{Sex and Age Differences in Meals Consumption}

While the analysis was performed to evaluate the frequency of consumption or skipping particular meals with respect to age and gender, it was shown that breakfast, lunch and supper are regularly eaten only by some of the examined adolescents.

Breakfast was statistically significantly consumed more often by boys than by girls, and it was more typical of high school students. There were no significant differences in breakfast consumption between girls and boys from middle schools. Lunch has been the meal eaten most often, regardless of sex. Nevertheless, the percentage of adolescents consuming lunch decreased significantly in high school in proportion to age, a fact that was particularly noticeable among girls. In middle schools there were no differences between girls' and boys' lunch consumption. Supper was consumed significantly more often by boys, both from middle schools and high schools, with the differences between girls and boys becoming more visible in the older age group. In high school supper was skipped by $12.8 \%$ of girls and by $4.3 \%$ of boys. The proportion of girls who were seen to skip supper was higher, but the differences between younger and older girls were statistically non-significant. Second breakfast and dessert are the most frequent skipped meals. Second breakfast consumption was similar for all participants, regardless of their sex, but this meal has been omitted more frequently by students from middle schools. Nearly $40 \%$ of all questioned persons did not consume dessert. Dessert was skipped more often by girls, especially by high school girls In case of boys the tendency was reversed (Table 3). 
Table 3. The proportion between consumers and non-consumers of particular meals with regard to level of education.

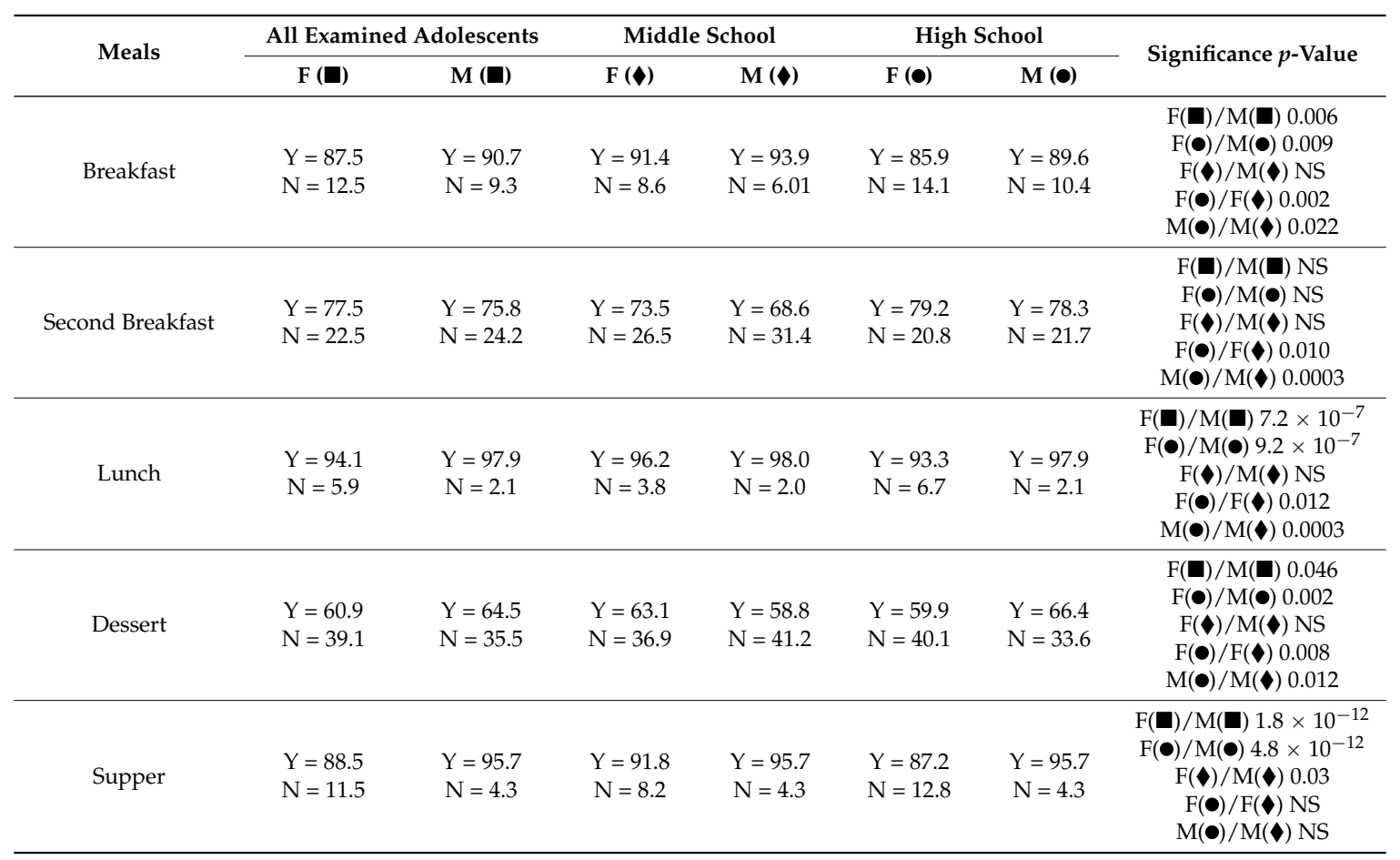

F-Female, M-Male; Y—\% of consumers; $\mathrm{N}-\%$ of non-consumers; NS-Not significant.

\subsection{Breakfast Consumption}

Students who eat breakfasts regularly, were seen to eat other meals as well, regardless of education level and sex. Among breakfast consumers there were both girls and boys, although being a girl predisposed to skip breakfast $(\mathrm{OR}=0.69)$. The level of education has been a differentiating variable-older teenagers consumed breakfasts more rarely than younger students. Students attending middle school ate breakfast nearly twice as often in comparison to high school students ( $\mathrm{OR}=1.66)$. Breakfast consumers were seen to eat supper three times more often $(\mathrm{OR}=3.0)$, lunch almost three times more often $(\mathrm{OR}=2.9)$ and second breakfast and dessert about one and a half time more often than breakfast skippers. There were no differences in BMI range between breakfast consumers and breakfast skippers (Table 4).

Table 4. Adjusted odds ratios for breakfast consumption with regard to sex, BMI, age (expressed as level of education) and other meals consumption.

\begin{tabular}{ccccc}
\hline Variables & OR & $\mathbf{2 . 5 \%}$ & $\mathbf{9 7 . 5 \%}$ & $p$ Value \\
\hline Sex (Female) & 0.69 & 0.51 & 0.83 & 0.0007 \\
BMI & 0.96 & 0.92 & 0.99 & 0.0421 \\
School (Middle school) & 1.66 & 1.25 & 2.24 & 0.0006 \\
Second breakfast (Y) & 1.59 & 1.23 & 2.04 & 0.0003 \\
Lunch (Dinner) (Y) & 2.88 & 1.87 & 4.35 & $7.7 \times 10^{-7}$ \\
Dessert (Y) & 1.51 & 0.17 & 0.66 & 0.0007 \\
Supper (Y) & 3.01 & 2.17 & 4.13 & $1.7 \times 10^{-11}$ \\
\hline
\end{tabular}




\subsection{Supper Consumption}

Supper was skipped significantly more often by girls $(\mathrm{OR}=0.35)$ than boys. BMI values were not influenced the supper consumption $(\mathrm{OR}=0.97)$. Supper was eaten nearly three times more often $(\mathrm{OR}=2.91)$ by breakfast consumers than breakfast skippers, and was consumed twice as often by persons who has eaten a second breakfast and dessert. Eating lunch had the biggest influence on supper consumption. Those persons ate supper nearly five times more often $(\mathrm{OR}=4.86)$ in comparison to persons who were seen to skip lunch (Table 5).

Table 5. Adjusted odds ratios for supper consumption with regard to sex, BMI, age (expressed as level of education) and other meals consumption.

\begin{tabular}{ccccc}
\hline Variables & OR & $\mathbf{2 . 5 \%}$ & $\mathbf{9 7 . 5 \%}$ & $p$ Value \\
\hline Sex (Female) & 0.35 & 0.25 & 0.48 & $3.6 \times 10^{-10}$ \\
BMI & 0.97 & 0.92 & 1.01 & NS \\
School (High school) & 1.48 & 0.84 & 2.67 & NS \\
Breakfast (Y) & 2.91 & 2.09 & 4.00 & $1.1 \times 10^{-10}$ \\
Second breakfast (Y) & 1.98 & 1.48 & 2.63 & $3.5 \times 10^{-6}$ \\
Lunch/Dinner (Y) & 4.86 & 3.19 & 7.32 & $7.6 \times 10^{-14}$ \\
Dessert (Y) & 2.05 & 1.54 & 2.72 & $5.8 \times 10^{-7}$ \\
\hline \multicolumn{5}{r}{ Y-consumers. }
\end{tabular}

\section{Discussion}

In Poland the National Nutrition Institute in Warsaw and the Polish Ministry of Health have created Food-Based Dietary Guidelines (FBDGs), which are disseminated in the form of 10 guidelines on healthy diet, healthy nutrition pyramid and general directives (http://www.izz.waw.pl/en/). According to the guidelines five daily meals are recommended and three main meals (breakfast, lunch, supper) are regarded as particularly important. The results of the presented study indicate that lunch is the meal eaten most often by adolescents, regardless of their sex, whilst the rest of meals are skipped more often by girls than boys. The habit of main meals being omitted is different among girls and boys and furthermore changes as they are getting older-adolescents from high schools eat main meals less often than adolescents from middle schools. Compared to younger children, worse food habits in adolescents could be explained by a higher degree of autonomy at this age and more freedom of decision making. The findings regarding age and gender variations are consistent with results from other countries [22,30-32]. The Health Behavior in School-aged Children (HBSC) results inform that about $30 \%$ of $11-15$ year old Polish adolescents do not eat breakfast every morning on school days and $20 \%-30 \%$ do not have any meal during school hours [33]. Breakfast is not consumed regularly by $12.5 \%$ of girls and $9.3 \%$ of examined boys. Among this group there were persons with BMI recommended for that age and sex and with BMI out of the norm, so normal BMI is not a sufficient marker of breakfast consumption habits Underweight participants (3.8\% of all examined) have also reported not consuming breakfast and other meals. It is possible that within this group persons at risk of developing eating disorders might be found. Overweight has been recognized in $14.9 \%$ of the examined students and mostly among boys. The 2009/2010 report of the Polish Institute of Mother and Child has stated that overweight is more frequent among boys, and the results of this paper seem to confirm that tendency [7]. Numerous studies have concluded that eating breakfast may reduce the risk of excess weight gain $[34,35]$. Several authors have demonstrated a relationship between skipping breakfast and higher BMI among different populations of children [36-38]. This study does not show such a strong correlation between overweight and breakfast skipping. BMI of breakfast consumers was only slightly lower than that of breakfast skippers' $(\mathrm{OR}=0.96 ; p<0.042)$. The reason of overweight may be an excess intake of calories, that starts with breakfast. Normal BMI among breakfast skippers might indicate that their energy requirements are being satisfied by meals other than breakfast. The study 
was designed to evaluate the quantity of consumed meals, but the energy intake from diet has not been taken under consideration and should be taken into account in any further research on this topic. Breakfast skipping by some students with healthy BMI might be considered as the first sign of poor dietary habit development and the consequences of not eating breakfast might become visible in their adult life, when changes leading to lower metabolic rate, lower level of physical activity, and endocrine disruption occur. Childhood dietary habits are hard to break in future adult life and this is why it is essential to also intensify nutritional education among adolescents with normal BMI. It is important to keep in mind that BMI is only a proportion of total body weight to height, and among persons with normal BMI there can be those with unhealthy proportions between lean body mass and fat mass. Therefore methods evaluating body composition should be considered as a better measure than BMI in assessing nutritional status and maybe in assessing dietary habits. Special nutritional programs are created in Poland and in other countries to fight overweight and underweight among students and protect them from dangerous consequences of unhealthy dietary habits for their physical and mental development.

In the United States, School Breakfast Programs (SBP) have been created and schools have received subsidies for each breakfast they serve for students [27]. Low income students may eat free or reduced-cost breakfasts in this way. School participation varies by state and region. Some participating schools offer free breakfast to all students, others only to qualifying students. Breakfast can be served in the cafeteria before school starts or in classrooms as the school day begins [26]. In the United States nearly 90,000 schools participated in the SBP in the 2011-2012 school year and approximately 12.5 million children got free meals each day. About half of the low income children participated in the SBP [39]. There is a strong evidence that having access to the School Breakfast Program (SBP) cognition, attendance, and scholastic achievement, especially in nutrition of deficient or malnourished children may be improved [40,41]. High-quality universal breakfast programs that allow students to eat breakfast in the classroom are especially needed for youth who are not likely to get good food for the rest of a day [28]. There is a great diversity of programs and structures for healthy eating in schools in Europe but a national comprehensive policy regarding the prevention of obesity in schools does not yet exist in every European country $[21,42,43]$. To help deal with this issue the Healthy Eating and Physical Activity in Schools (HELPS) project has been developed to support countries in Europe in promoting healthy eating and physical activity at schools in a positive and sustainable way. This project is linked to the Schools for Health in Europe network [44].

In Poland, schools are obliged to carry out health education, including nutritional education $[45,46]$. In the new core curriculum, implemented in 2008, there are many topics related to healthy eating. The organization of school meals for all students, as well as the participation of schools in obesity prevention programs were not satisfactory, but now activities to prevent overweight are specified in the 2007-2015 National Health Program [47]. Information obtained from 520 randomly selected primary, lower-secondary and cluster schools from all the voivodeships of Poland showed that in some ongoing national programs like "A Glass of Milk" the participation rate was $74 \%$ (only $25 \%$ of the lower secondary schools) and in "Fruit at School" 38\% (6\% of lower secondary schools) respectively. The "Keep Fit" educational program was implemented in $28 \%$ of primary schools and in $72 \%$ of lower secondary schools [45]. Nevertheless the majority of schools in Poland still treat students' need to eat a meal at school as a minor problem and are not involved in any activities focusing on prevention of obesity. The undertaken activities are incoherent and there is a need to create a healthy nutrition policy on the national, regional, local and school level.

\section{Conclusions}

The findings have confirmed the importance of proper nutritional education among adolescents and indicate that students who consumed breakfast regularly are also likely to eat other meals. This fact might lead to conclusion that breakfast consumption encourages consumption of more meals during a day, but as obesity has become a global issue it is necessary to pay more attention to energy and nutrient 
intake. The habits of main meals consumption differ among girls and boys and changes as they get older-adolescents from high schools eat main meals less often than middle school students. BMI of breakfast consumers and non-consumers did not differ significantly in the examined adolescents-this might suggest that BMI is an insufficient marker of regularity of breakfast consumption and the dietary habits of adolescents. It is likely that the consequences of not consuming breakfast will be recognized in the nutritional status during future adult life, when breaking dietary habits is more difficult. To verify that thesis future research will be undertaken.

Acknowledgments: The authors thank students who participated in this study. We would like to also thank the editor and reviewers for the constructive review comments.

Author Contributions: Agnieszka Ostachowska-Gasior designed the study, analyzed and interpreted the results, prepared the manuscript, searched the literature, wrote the paper, and performed the manuscript review; Monika Piwowar performed the statistical analyses; Agata Skop-Lewandowska and Jacek Kwiatkowski oversaw interpretation of data, recruitment and questionnaire administration and participated in the design of the study; Janusz Kasperczyk collected the research material. All authors approved the final version.

Conflicts of Interest: The authors declare no conflict of interest.

\section{References}

1. Sawyer, S.M.; Afifi, R.A.; Bearinger, L.H.; Blakemore, S.J. Adolescence: A foundation for future health. Lancet 2012, 379, 1630-1640. [CrossRef]

2. Currie, C.; Morgan, A.; Currie, D.; de Looze, M.; Roberts, C.; Samdal, O.; Smith, O.R.F.; Barnekow, V. Social Determinants of Health and Well-Being among Young People. Health Behaviour. In School-Aged Children (HBSC) Study; International Report from 2009/2010 Survey; WHO Regional Office for Europe: Copenhagen, Denmark, 2012.

3. Affenito, S.G. Breakfast: A missed opportunity. J. Am. Diet. Assoc. 2007, 107, 565-569. [CrossRef] [PubMed]

4. Fismen, A.S.; Smith, O.R.; Torsheim, T.; Samdal, O. A school based study of time trends in food habits and their relation to socio-economic status among Norwegian adolescents, 2001-2009. Int. J. Behav. Nutr. Phys. Act. 2014, 11, 115. [CrossRef] [PubMed]

5. CDC U.S. Department of Health and Human Services. Youth Risk Behavior Surveillance; CDC U.S. Department of Health and Human Services: Atlanta, GA, USA, 2009; Volume 59, p. S5.

6. Lien, N.; Jacobs, D.R., Jr.; Klepp, K.I. Exploring predictors of eating behaviour among adolescents by gender and socio-economic status. Public Health Nutr. 2002, 5, 671-681. [CrossRef] [PubMed]

7. Weker, H.; Baranska, M. Models of safe nutrition of children and adolescents as a basis for prevention of obesity. Med. Wieku Rozwoj. 2011, 15, 288-297. [PubMed]

8. Millar, L.; Rowland, B.; Nichols, M.; Swinburn, B.; Bennett, C.; Skouteris, H.; Allender, S. Relationship between raised BMI and sugar sweetened beverage and fat food consumption among children. Obesity 2014, 22, E96-E103. [CrossRef] [PubMed]

9. Laska, M.N.; Murray, D.M.; Lytle, L.A.; Harnack, L.J. Longitudinal associations between key dietary behaviours and weight gain over time: Transitions trhough the adolescent years. Obesity 2012, 20, 118-125. [PubMed]

10. Kołłataj, W.; Sygit, K.; Sygit, M.; Karwat, I.D.; Kołłataj, B. Eating habits of children and adolescents from rural regions depending on gender, education, and economic status of parents. Ann. Agric. Environ. Med. 2011, 18, 393-397. [PubMed]

11. Szajewska, H.; Ruszczynski, M. Systematic review demonstrating that breakfast consumption influences body weight outcomes in children and adolescents in Europe. Crit. Rev. Food Sci. Nutr. 2010, 50, 113-119. [PubMed]

12. World Health Organization. Diet, Nutrition and Prevention of Chronic Diseases. World Health Organization: Geneva, Switzerland, 2003. Available online: http://www.who.int/dietphysicalactivity/ publications/trs916/download/en/ (accessed on 4 November 2015).

13. Kutsuma, A.; Nakajima, K.; Suwa, K. Potential Association between Breakfast Skipping and Concomitant Late-Night-Dinner Eating with Metabolic Syndrome and Proteinuria in the Japanese Populations 2014, 253581. Available online: http://dx.doi.org/10.1155/2014/253581 (accessed on 10 September 2015). 
14. CDC U.S. Department of Health and Human Services. School Health Guidelines to Promote Healthy Eating and Physical Activity Recommendations and Reports; CDC U.S. Department of Health and Human Services: Atlanta, GA, USA, 2011; Volume 60, pp. 1-71.

15. Tuckson, R.V. America's childhood obesity crisis and the role of schools. J. Sch. Health 2013, 83, 137-138. [PubMed]

16. Daniels, S.R. Complications of obesity in children and adolescents. Int. J. Obes. (Lond.) 2009, 33, 60-65.

17. Horikawa, C.; Kodama, S.; Yachi, Y.; Heianza, Y.; Hirasawa, R.; Ibe, Y.; Saito, K.; Shimano, H.; Yamada, N.; Sone, H. Skipping breakfast and prevalence of overweight and obesity in Asian and Pacific regions: A meta-analysis. Prev. Med. 2011, 53, 260-267. [PubMed]

18. Brown, A.W.; Bohan Brown, M.M.; Allison, D.B. Belief beyond the evidence: Using the proposed effect of breakfast on obesity to show 2 practices that distort scientific evidence. Am. J. Clin. Nutr. 2013, 98, 1298-1308. [CrossRef] [PubMed]

19. Behrens, B. Is Breakfast or Breakfast Skipping Associated with Adiposity in Adults? Methodological Considerations. Master's Thesis, CFS Honors Program Undergraduate, Purdue University, West Lafayette, IN, USA, 2009.

20. Schusdziarra, V.; Hausmann, M.; Wittke, C.; Mittermeier, J.; Kellner, M.; Naumann, A. Impact of breakfast on daily energy intake-An analysis of absolute versus relative breakfast calories. Nutr. J. 2011, 10, 1-8. [CrossRef] [PubMed]

21. Moore, L.; Moore, G.F.; Tapper, K.; Lynch, R.; Desousa, C.; Hale, J. Free breakfasts in schools: Design and conduct of a cluster randomized controlled trial of the Primary School Free Breakfast Initiative in Wales. BMC Public Health 2007, 7, 258. [CrossRef] [PubMed]

22. Voracova, J.; Sigmund, E.; Sigmundova, D.; Kalman, M. Changes in Eating Behaviours among Czech Children and Adolescents from 2002 to 2014 (HBSC Study). Int. J. Environ. Res. Public Health 2015, 12, 15888-15899. [CrossRef] [PubMed]

23. Cheng, T.S.; Tse, L.A.; Yu, I.T.; Griffiths, S. Children's perceptions of parental attitude affecting breakfast skipping in primary sixth-grade students. J. Sch. Health 2008, 78, 203-208. [CrossRef] [PubMed]

24. Wright, J.A.; Whiteley, J.A.; Laforge, R.G.; Adams, W.G.; Berry, D.; Friedman, R.H. Validation of 5 Stage-of-Change Measures for Parental Support of Healthy Eating and Activity. J. Nutr. Educ. Behav. 2015, 47, 134-142. [CrossRef] [PubMed]

25. Burgess-Champoux, T.L.; Larson, N.; Neumark-Sztainer, D.; Hannan, P.J.; Story, M. Are family meal patterns associated with overall diet quality during the transition from early to middle adolescence? J. Nutr. Educ. Behav. 2009, 41, 79-86. [CrossRef] [PubMed]

26. Kessler, H.L.; Vine, J.; Rogers, V.W. Let's Go! School Nutrition Workgroups: Regional Partnerships for Improving School Meals. J. Nutr. Educ. Behav. 2015, 47, 278-282. [CrossRef] [PubMed]

27. Bartfeld, J.; Kim, M. Participation in the School Breakfast Program: New evidence from the ECLS-K. Soc. Serv. Rev. 2010, 84, 541-562. [CrossRef] [PubMed]

28. Gleason, P.M.; Dodd, A.H. School breakfast program but not school lunch program participation is associated with lower body mass index. J. Am. Diet. Assoc. 2009, 109 (Suppl. 2), 118-128. [CrossRef] [PubMed]

29. Kułaga, Z.; Litwin, M.; Tkaczyk, M.; Palczewska, I.; Zajączkowska, M.; Zwolińska, D.; Krynicki, T.; Wasilewska, A.; Moczulska, A.; Morawiec-Knysak, A.; et al. Polish 2010 growth references for school-aged children and adolescents. Eur. J. Pediatr. 2011, 170, 599-609. [CrossRef] [PubMed]

30. Alexy, U.; Wicher, M.; Kersting, M. Breakfast trends in children and adolescents: Frequency and quality. Public Health Nutr. 2010, 13, 1795-1802. [CrossRef] [PubMed]

31. Levin, K.A.; Kirby, J.; Currie, C.; Inchley, J. Trends in adolescent eating behaviour: A multilevel cross-sectional study of 11-15 year olds in Scotland, 2002-2010. J. Public Health 2012, 34, 523-531. [CrossRef] [PubMed]

32. Inchley, J.; Todd, J.; Bryce, C.; Currie, C. Dietary trends among Scottish schoolchildren in the 1990s. J. Hum. Nutr. Diet. 2001, 14, 207-216. [CrossRef] [PubMed]

33. Mazur, J.; Woynarowska, B.; Kołoło, H. Zdrowie Subiektywne, Styl Zycia i Srodowisko Psychospołeczne Młodziezy Szkolnej w Polsce; Institute of Mother and Child: Warsaw, Poland, 2007.

34. Elinder, L.S.; Heinemans, N.; Zeebari, Z.; Patterson, E. Longitudinal changes in health behaviours and body weight among Swedish school children-Associations with age, gender and parental education-The skip school cohort. BMC Public Health 2014, 14, 640. [CrossRef] [PubMed] 
35. Deshmukh-Taskar, P.R.; Nicklas, T.A.; O'Neil, C.E.; Keast, D.R.; Radcliffe, J.D.; Cho, S. The relationship of breakfast skipping and type of breakfast consumption with nutrient intake and weight status in children and adolescents: The National Health and Nutrition Examination Survey 1999-2006. J. Am. Diet. Assoc. 2010, 110, 869-878. [CrossRef] [PubMed]

36. Timlin, M.T.; Pereira, M.A. Breakfast frequency and quality in the etiology of adult obesity and chronic diseases. Nutr. Rev. 2007, 65, 268-281. [CrossRef] [PubMed]

37. Timlin, M.T.; Pereira, M.A.; Story, M.; Neumark-Sztainer, D. Breakfast eating and weight change in 5-year prospective analysis of adolescents: Project EAT (Eating Among Teens). Pediatr. Ann. 2008, 121, 638-645. [CrossRef] [PubMed]

38. Quick, V.; Wall, M.; Larson, N.; Haines, J.; Neumark-Sztainer, D. Personal, behavioral and socio-environmental predictors of overweight incidence in young adults: 1-yr longitudinal findings. Int. J. Behav. Nutr. Phys. Act. 2013, 10, 37-39. [CrossRef] [PubMed]

39. Hewins, J.; Levin, M. School Breakfast Scorecard: School Year 2011-2012; Food Research and Action Center (FRAC): Washington, DC, USA, 2013.

40. Hoyland, A.; Dye, L.; Lawton, C.L. A systematic review of the effect of breakfast on the cognitive performance of children and adolescents. Nutr. Res. Rev. 2009, 22, 220-243. [CrossRef] [PubMed]

41. Basch, C.E. Breakfast and the achievement gap among urban minority group. J. Sch. Health 2011, 81, 635-640. [CrossRef] [PubMed]

42. Defeyter, M.A.; Graham, P.L.; Walton, J.; Apicella, T. Breakfast clubs: Availability for British schoolchildren and the nutritional, social and academic benefits. Nutr. Bull. 2010, 35, 245-253. [CrossRef]

43. Mhurchu, C.N.; Gorton, D.; Turley, M.; Jiang, Y.; Michie, J.; Maddison, R.; Hattie, J. Effects of a free school breakfast programme on children's attendance, academic achievement and short-term hunger: Results from a stepped-wedge, cluster randomised controlled trial. J. Epidemiol. Community Health 2013, 67, 257-264. [CrossRef] [PubMed]

44. Boonen, A.; de Vries, N.; de Ruiter, S.; Bowker, S.; Buijs, G. HELPS Guidelines. NIGZ, Voerden. Available online: http:/ / www.hepseurope.eu (accessed on 12 March 2011).

45. Woynarowska, B.; Małkowska-Szkutnik, A.; Mazur, J.; Kowalewska, A.; Komosińska, K. School meals and policy on promoting healthy eating in schools in Poland. Med. Wieku Rozwoj. 2011, 15, 232-239. [PubMed]

46. Gurzkowska, B.; Grajda, A.; Kułaga, Z.; Napieralska, E.; Litwin, M. OLAF Study Group: Normal weight, underweight, overweight and obesity among Polish children and youth in rural and urban areas. Med. Wieku Rozwoj. 2011, 15, 145-157.

47. National Health Programme 2007-2015. Available online: http://www.mz.gov.pl (accessed on 7 September 2015). 